\title{
Félicie Pastoré, Can you? Testez vos connaissances en
} anglais de la santé

Paris : Ellipses, 2013

\section{Pascaline Faure}

\section{OpenEdition \\ Journals}

Édition électronique

URL : http://journals.openedition.org/asp/4559

DOI : 10.4000/asp.4559

ISSN : 2108-6354

\section{Éditeur}

Groupe d'étude et de recherche en anglais de spécialité

\section{Édition imprimée}

Date de publication : 1 novembre 2014

Pagination : 171-172

ISSN : 1246-8185

\section{Référence électronique}

Pascaline Faure, "Félicie Pastoré, Can you? Testez vos connaissances en anglais de la santé », ASp [En ligne], 66 | 2014, mis en ligne le 27 octobre 2014, consulté le 03 novembre 2020. URL : http:// journals.openedition.org/asp/4559; DOI : https://doi.org/10.4000/asp.4559

Ce document a été généré automatiquement le 3 novembre 2020.

Tous droits réservés 


\section{Félicie Pastoré, Can you? Testez vos connaissances en anglais de la santé}

Paris : Ellipses, 2013

Pascaline Faure

\section{RÉFÉRENCE}

Pastoré, Félicie. 2013. Can you? Testez vos connaissances en anglais de la santé. Paris :

Ellipses, 190 p. ISBN : 978-2-729-88154-2. 
1 Can you? Testez vos connaissances en anglais de la santé est la compilation des épreuves proposées de 2007 à 2012 aux étudiants en médecine de la deuxième (PCEM2/ DFGSM2) à la quatrième année (DCEM3) de la Faculté Toulouse-Purpan. Il rassemble les modalités d'évaluation des connaissances et des compétences des étudiants, les sujets ainsi que leurs corrigés. Il est destiné aux professionnels de santé désireux de travailler en autonomie. Les épreuves de compréhension orale et de résumé sont construites à partir de documents authentiques accessibles en ligne via un lien. Quelques liens ne sont malheureusement accessibles qu'avec un abonnement payant (notamment $<$ www.time.com> p.23). Certaines
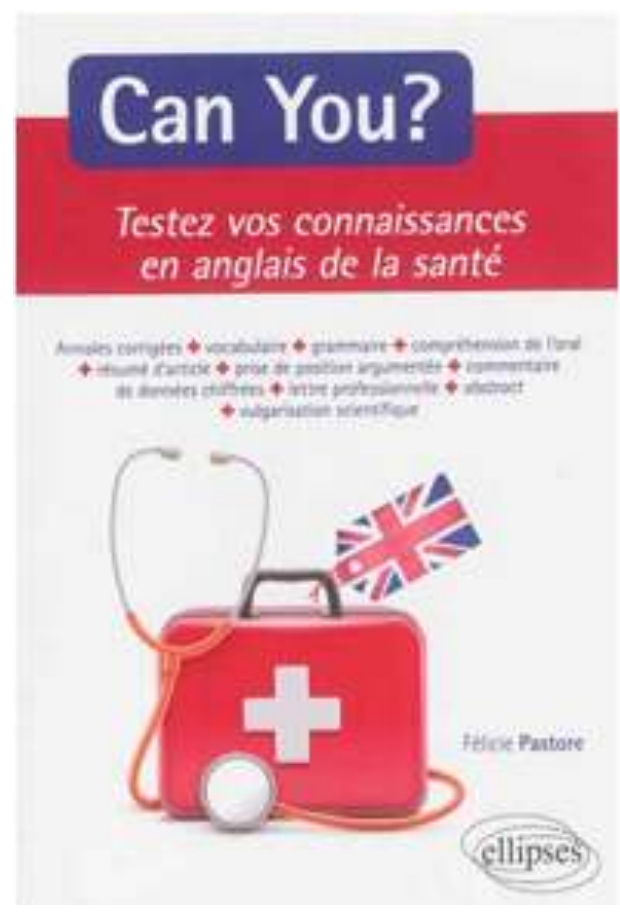
épreuves de vocabulaire sont extraites de l'ouvrage L'anglais pour la santé (2013), co-écrit par Félicie Pastoré. Un certain nombre de questions (PCEM2 2007-2008 p. 16 et DCEM1 2010-2011 p. 141) portent sur le contenu d'une conférence de virologie, mais aucune information sur la façon d'accéder au document n'est donnée. Il en va de même pour les conférences sur medical education, alcohol et viral infections pages 79 et 82. Les annales de PCEM2 (86 pages) sont une alternance d'exercices de compréhension orale, de vocabulaire, de grammaire (utilisation des temps, questionnement), de traduction (thème et version) et de résumés structurés de 120 à 150 mots (à partir d'articles courts de vulgarisation scientifique). Les thématiques sont variées (grippe, sida, études de médecine, relation médecin/patient, etc.). Certains sujets sont notés "niveau 1 » et d'autres " niveau 5 » sans que cette gradation soit expliquée et ils intègrent parfois les mêmes exercices (p. 79 et p. 82).

2 Les annales de DCEM1/DFGSM3 (70 pages) comprennent des épreuves de compréhension orale à partir de questions moins guidées, des résumés (en 250 mots) portant sur des articles plus longs, des commentaires de données chiffrées (en 150 mots), des rédactions de courriers professionnels, des prises de position argumentée, des exercices de grammaire et vocabulaire ainsi que des QCM. On note une entrée progressive dans le spécialisé professionnel avec la rédaction de referral letters à partir de notes et une initiation à la consultation (écrite). Là encore, les thématiques sont variées (sécurité des médicaments, choléra, maladies cardiovasculaires, etc.).

3 Les annales de DCEM2 (11 pages) incluent la rédaction d'un abstract de 300 mots (à partir d'un article de recherche scientifique) et une prise de position argumentée (en 150-180 mots). Celles de DCEM3 (11 pages) proposent des exemples d'épreuves de rédaction d'un article de vulgarisation de 350 mots.

$4 \quad$ Il est assez improbable que des apprenants en autonomie trouvent un intérêt dans l'ouvrage. La présentation est peu engageante puisqu'il s'agit de la reproduction directe de sujets d'examen. En revanche, ces annales devraient se révéler très utiles aux 
enseignants d'anglais médical à la Faculté de médecine. Elles constituent une banque de sujets corrigés extrêmement riche. Par ailleurs, les modalités d'évaluation des connaissances et des compétences des étudiants ainsi que l'entrée progressive dans le spécialisé professionnel pourront guider les enseignants novices (ou non) dans la mise en place et dans l'évaluation de formations d'anglais pour la santé dans leur établissement.

\section{BIBLIOGRAPHIE}

Carnet, Didier, Sylvia Morgan et Félicie Pastoré. 2013. L'anglais pour la santé. Exercices d'appropriation de la langue à visée professionnelle. $3^{\mathrm{e}}$ édition. Paris : Ellipses.

\section{AUTEURS}

\section{PASCALINE FAURE}

Université Pierre et Marie Curie, Paris 6. pascalinefaure@orange.fr 